\title{
Protective effect of adipose-derived mesenchymal stem cells against acute kidney injury induced by ischemia-reperfusion in Sprague-Dawley rats
}

\author{
HUSSEIN SHEASHAA $^{1 *}$, AHMED LOTFY ${ }^{2 *}$, FATMA ELHUSSEINI $^{3}$, AZZA ABDEL AZIZ $^{3}$, AZZA BAIOMY $^{4}$, \\ SAMAH AWAD ${ }^{2}$, AZIZA ALSAYED ${ }^{2}$, ABDEL-HADY EL-GILANY ${ }^{5}$, MOHAMED-AHDY A.A. SAAD ${ }^{6}$, \\ KHALED MAHMOUD $^{1}$, FATEN ZAHRAN ${ }^{7}$, DALIA A. SALEM ${ }^{4}$, AHMED SARHAN ${ }^{1}$, \\ HASSAN ABDEL GHAFFAR ${ }^{4}$ and MOHAMED SOBH ${ }^{1,2}$ \\ ${ }^{1}$ Urology and Nephrology Center; ${ }^{2}$ Medical Experimental Research Center (MERC), Faculty of Medicine, \\ Mansoura University, Mansoura 35516; Departments of ${ }^{3}$ Pathology, ${ }^{4}$ Clinical Pathology, ${ }^{5}$ Public Health and \\ ${ }^{6}$ Pharmacology, Faculty of Medicine, Mansoura University, Mansoura 35516; ${ }^{7}$ Biochemistry Department, \\ Faculty of Science, Zagazig University, Zagazig 44516, Egypt
}

Received December 27, 2014; Accepted December 1, 2015

DOI: 10.3892/etm.2016.3109

\begin{abstract}
Acute kidney injury (AKI) is a complex clinical condition associated with significant morbidity and mortality and lacking effective management. Ischemia-reperfusion injury (IRI) remains one of the leading causes of AKI in native and transplanted kidneys. The aim of this study was to evaluate the efficacy of adipose-derived mesenchymal stem cells (ADSCs) in the prevention of renal IRI in rats. The study was conducted on male Sprague-Dawley rats $(n=72)$ weighing 250-300 g. Rats were randomly assigned to three main groups: i) Sham-operated control group $(n=24)$; ii) positive control group, in which rats were subjected to IRI and were administered culture media following $4 \mathrm{~h}$ of IRI $(n=24)$; and iii) ADSC group ( $n=24)$, in which rats were administered $1 \times 10^{6}$ ADSCs via the tail vein following $4 \mathrm{~h}$ of IRI. Each main group was further divided according to the timing after IRI into four equal-sized subgroups. Renal function was tested via the measurement of serum creatinine levels and creatinine clearance. In addition, malondialdehyde (MDA) levels were determined in serum and renal tissue homogenate as an indicator of oxidative stress. Histopathological changes were analyzed in different regions of the kidney, namely the cortex, outer stripe of the outer medulla (OSOM), inner stripe of the outer medulla (ISOM) and inner medulla. In
\end{abstract}

Correspondence to: Dr Ahmed Lotfy, Medical Experimental Research Center (MERC), Faculty of Medicine, Mansoura University, 60 El Gomhoria Street, Mansoura 35516, Egypt

E-mail: lotfy_bio@hotmail.com

*Contributed equally

Key words: acute kidney injury, rats, ischemia reperfusion injury, adipose derived mesenchymal stem cell each region, the scoring system considered active injury changes, regenerative changes and chronic changes. The ADSCs were assessed and their differentiation capability was verified. IRI resulted in a significant increase in serum creatinine, serum and tissue MDA levels and a significant reduction in creatinine clearance compared with those in sham-operated rats,. These changes were attenuated by the use of ADSCs. The prominent histopathological changes in the cortex, ISOM and OSOM were reflected in the injury score, which was significantly evident in the positive control group. The use of ADSCs was associated with significantly lowered injury scores at days 1 and 3; however, no significant effect was observed on day 7 . These results indicate that the use of ADSCs ameliorates renal injury and dysfunction associated with IRI in rats.

\section{Introduction}

Acute kidney injury (AKI) is a complex clinical problem associated with significant short-term morbidity and mortality (up to $50 \%$ ) (1), and lacking effective pharmacologic interventions. Patients with AKI experience longer-term risks for progressive end stage renal disease, which diminishes the health-related quality of life of a patient and creates a burden on the healthcare system (2). Renal ischemia-reperfusion injury (IRI) is one of the leading causes of AKI in both native and transplanted kidneys $(3,4)$.

The damaging effects of renal IRI comprise a complex interrelated sequence of events, eventually resulting in apoptosis and necrosis of the renal cells (5). One of these events is the endothelial stress as described by Brodsky and Goligorsky (6) where the concept of 'no-reflow' is adopted in addition to the consequence of cellular cross-talk dialog between the epithelium and endothelium in response to renal ischemia. Reactive oxygen species burst is another underlying mechanism of AKI during the reperfusion of ischemic tissues, in which reactive oxygen species stimulate the generation of inflammatory 
cytokines, pro-apoptotic mediators and further oxidative stress (7). The high morbidity and mortality rates associated with IRI/AKI and unsatisfactory results from currently available clinical therapeutic approaches have prompted further research (8). This has included the investigation of stem cells, which are undifferentiated cells able to renew and differentiate into one or more cell types that have the potential to ameliorate IRI (8). In particular, mesenchymal stem cells (MSCs), which are multi-potent adult stem cells that have multi-lineage differentiation potential and immunosuppressive properties are suggested to be an ideal candidate cell-type for immunomodulation and regenerative medicine (9). Furthermore, adipose-derived stem cells (ADSCs) are an emerging cellular therapy (10). The plasticity of ADSCs and their ability to differentiate into cells of mesodermal origin, such as adipocyte, osteocyte, chondrocyte and myocyte lineages have been demonstrated $(11,12)$.

The aim of the present study was to evaluate the effect of ADSCs on renal IRI. In addition, renal histopathological changes were assessed using a new histopathological scoring system that evaluates features associated with both injury and regeneration.

\section{Materials and methods}

Ethical approval. The experimental protocol was approved by the Local Ethical Committee or the Faculty of Medicine, Mansoura University (Mansoura, Egypt).

\section{Isolation and characterization of ADSCs}

Isolation. The isolation of MSCs from adipose tissue was conducted as previously described by Bunnell et al (13). The cells were maintained in an incubator supplied with a humidified atmosphere of $5 \% \mathrm{CO}_{2}$ at $37^{\circ} \mathrm{C}$. Cell cultivation was maintained up to the third passage, and cells were then characterized by immunophenotypic and differentiation capability.

Characterization by flow cytometric analysis. Cells were characterized using cell surface markers by fluorescence-activated cell sorting (FACS) analyses. The cells were stained with different fluorescently labeled monoclonal antibodies, including fluorescein isothiocyanate-conjugated anti-rat CD45 (11-0461), phycoerythrin (PE)-conjugated anti-rat CD29 (12-0291) and PE/Cy5-conjugated CD90 (15-0900) (all: eBioscience, Inc., San Diego, CA, USA). The fluorescence intensity of the cells was evaluated by flow cytometry using an EPICS-XL instrument (Beckman Coulter, Miami, FL, USA).

Differentiation capability. i) Osteogenic differentiation. ADSCs at the third passage were seeded in a 6-well plate ( 0.03 million cells/well), and when they were $80 \%$ confluent, osteogenesis differentiation medium was added to 4 of the wells, comprising: Dulbecco's modified Eagle's medium (DMEM) supplemented with $10 \%$ fetal bovine serum (FBS), $0.1 \mu \mathrm{M}$ dexamethasone, $50 \mu \mathrm{M}$ ascorbic acid and $10 \mathrm{mM}$ $\beta$-glycerol phosphate (all Sigma-Aldrich, St. Louis, MO, USA).Complete culture medium, consisting of DMEM and FBS, was added to the other 2 wells as a negative control. The medium was changed twice per week for 2-3 weeks. The differentiation potential for osteogenesis was assessed by staining with 40 mM Alizarin Red (pH 4.1; Sigma-Aldrich) following fixation in $10 \%$ neutral-buffered formalin (Sigma-Aldrich). ii) Adipogenic differentiation. ADSCs at the third passage were seeded in a 6-well plate ( 0.2 million cells/well), and when they were $100 \%$ confluent, adipogenesis differentiation medium was added to 4 of the wells, comprising: DMEM supplemented with $10 \%$ FBS, $1 \mu \mathrm{M}$ dexamethasone, $500 \mu \mathrm{M}$ isobutylmethylXanthine (IBMX), $5 \mu \mathrm{g} / \mathrm{ml}$ insulin and $200 \mu \mathrm{M}$ indomethacin (Sigma-Aldrich); and complete culture medium was added to the other 2 wells as a negative control. The medium was changed twice per week for 2 weeks. The differentiation potential for adipogenesis and the formation of intracellular lipid droplets were assessed by staining with Oil Red O (Sigma-Aldrich) following fixation in $10 \%$ neutral buffered formalin.

Animal grouping and renal ischemia/reperfusion model. This study was conducted using male Sprague-Dawley rats ( $\mathrm{n}=72$; Charles River Laboratories, Wilmington, MA, USA) weighing 250-300 g. The model of IRI was created as described by Jablonski et al (14) with modifications, as described below. The rats were anesthetized by the administration of diazepam [15 mg/kg, intraperitoneally (i.p.)] and ketamine (150 mg/kg, i.p.; both Sigma-Aldrich). The inhalation of halothane (Sigma-Aldrich) was used to prolong the duration of anesthesia when necessary. Through a midline incision, the abdominal cavity was exposed and the left renal pedicle was isolated and clamped with a non-traumatic arterial clamp for $45 \mathrm{~min}$. Immediately prior to removal of the clamp, the right kidney was exposed extracorporeally, its pedicle was ligated with a $4 / 0$ silk suture, and the kidney was removed from the abdominal cavity. The occlusion and reperfusion of the left kidney were verified visually by the observation of changes in color. Afterwards, $1 \mathrm{ml}$ saline at $37^{\circ} \mathrm{C}$ was injected into the abdomen and the incision was sutured in two layers. Using a warming light, the temperature was adjusted to $\sim 37^{\circ} \mathrm{C}$.

The rats were randomly assigned to three groups, as follows ( $n=24 /$ group): i) The sham-operated control group, in which the rats were maintained under anesthesia for $45 \mathrm{~min}$ and underwent surgery without the occlusion of the left renal pedicle; ii) the positive control group, in which the rats were subjected to IRI modeling and were administered culture media following $4 \mathrm{~h}$ of IRI; and iii) the ADSC group, in which the rats were administered $1 \times 10^{6}$ ADSCs via the tail vein following $4 \mathrm{~h}$ of IRI modeling. In addition, each group was further divided into four subgroups according to the time post-IRI ( $n=6 /$ subgroup): Subgroup A rats were sacrificed $24 \mathrm{~h}$ post-renal IRI injury; subgroup B rats were sacrificed 3 days post-renal IRI injury; subgroup $C$ rats were sacrificed 7 days post-renal IRI; and subgroup D rats were sacrificed 14 days post-IRI. Prior to sacrifice, a 24 h-urine sample was collected using a metabolic cage. Rats were sacrificed by the administration of an overdose of thiopental. Blood samples were collected from the heart and immediately centrifuged using the Hettich Universal 32R centrifuge (DJB Labcare Ltd., Buckinghamshire, UK) at $3,000 \mathrm{x}$ g for $5 \mathrm{~min}$ at room temperature, then taken for biochemical measurements. The left kidney was removed for histological evaluation.

Biochemical measurements. Renal function tests (serum creatinine and creatinine clearance) were conducted using a commercially available kit (CREATININE liquicolor; 
A

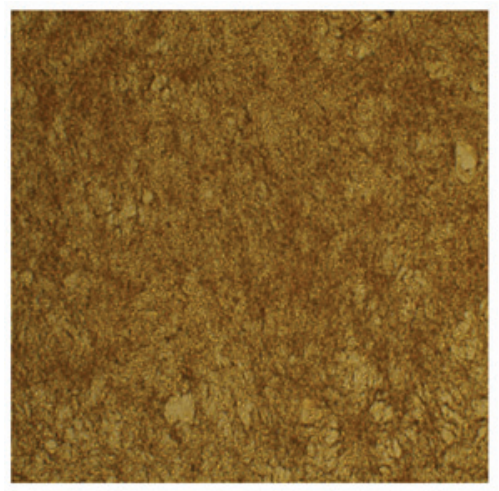

C

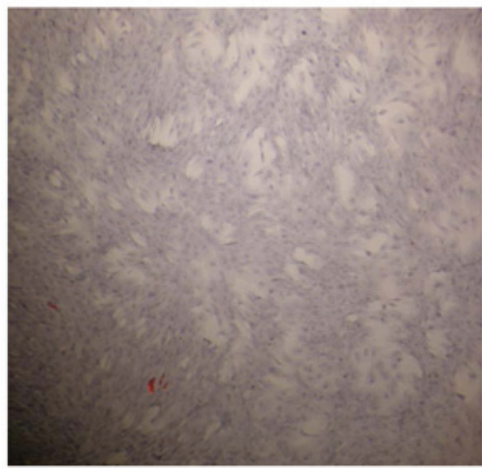

B

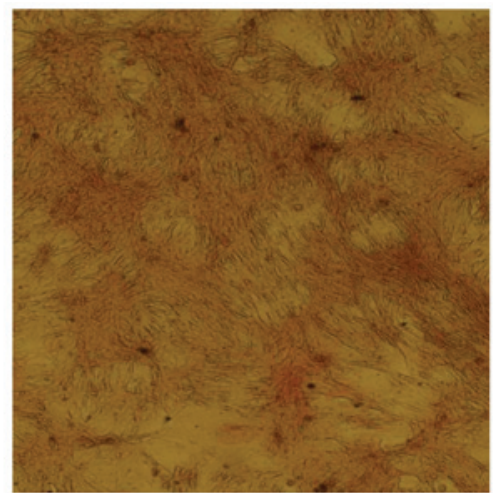

D

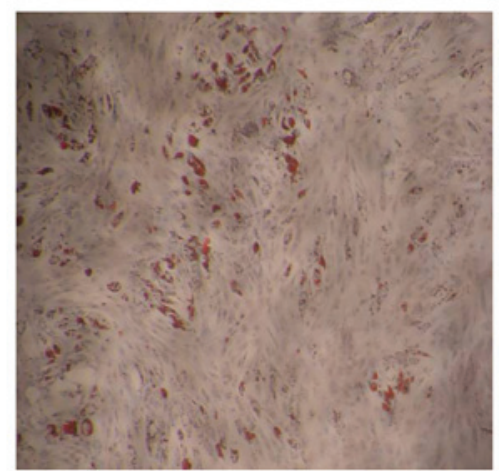

Figure 1. Differentiation of rat adipose-derived mesenchymal stem cells (ADSCs): (A) Undifferentiated and (B) osteogenically differentiated rat ADSCs stained with Alizarin Red. (C) Undifferentiated and (D) adipogenically differentiated rat ADSCs stained with Oil Red O (magnification, x4).

HUMAN Gesellschaft für Biochemica und Diagnostica mbH, Wiesbaden, Germany). Creatinine clearance was calculated using the following formula: Creatinine clearance $(\mathrm{ml} / \mathrm{min})=\mathrm{U} \times \mathrm{V} / \mathrm{P}$. Where $\mathrm{U}(\mathrm{mg} / \mathrm{dl})$ is the concentration of creatinine in urine, $\mathrm{P}(\mathrm{mg} / \mathrm{dl})$ is the concentration of creatinine in plasma and $\mathrm{V}$ is the volume of urine collected in a duration of time (min).

Malondialdehyde (MDA) levels in the serum (nmol/ml) and renal tissue MDA (nmol/g) were determined spectrophotometrically in all groups. Briefly, blood samples were left for $20 \mathrm{~min}$ to allow clotting, after which they were centrifuged at $1,500 \mathrm{x} g$ for $5 \mathrm{~min}$ at room temperature to obtain serum, which was stored at $-80^{\circ} \mathrm{C}$ until further analysis. Prior to dissection, renal tissues were perfused with phosphate-buffered saline ( $\mathrm{pH} 7.4$ ) containing $0.16 \mathrm{mg} / \mathrm{ml}$ heparin (Sigma-Aldrich) to remove blood cells or clots. Subsequently, the tissues were homogenized in cold potassium phosphate buffer $(50 \mathrm{mM}$; Sigma-Aldrich) and then centrifuged at 1,792 x g for $15 \mathrm{~min}$. The supernatant was separated and maintained at $-80^{\circ} \mathrm{C}$ until further analysis. MDA levels were determined using the MDA Assay kit (NWK-MDA01; Northwest Life Science Specialties, LLC, Portland, WA, USA) in which MDA reacts with thiobarbituric acid to form a colorimetric product that was measured at $532 \mathrm{~nm}$ using the Jenway 7305 spectrophotometer (Bibby Scientific Ltd., Staffordshire, UK).

\section{Renal histopathology}

Histopathological analysis. Perfusion fixation of the whole animal was conducted and one half of the left kidney was processed for light microscopic observation, according to standard procedures. The kidneys were preserved in $10 \%$ neutral buffered formalin, after which the kidneys were embedded in paraffin wax, cut into $4-\mu \mathrm{m}$ sections, and stained with hematoxylin and eosin (H\&E). Histopathological changes were analyzed in the different regions of the kidney, specifically, in the cortex, outer stripe of the outer medulla (OSOM), inner stripe of the outer medulla (ISOM) and inner medulla. In each layer, scores were calculated using a scoring system that considered active injury changes, regenerative changes and chronic changes:

Active injury scoring. Changes associated with active injury included necrotic tubules and interstitial infiltration by inflammatory cells. The degree of tubular injury was quantified according to the number of necrotic tubules counted per high power field (HPF). Necrotic tubules were given a score of $1,2,3$ or 4 , corresponding to $1-3,4-5,6-10$ and $>10$ per HPF, respectively.

Scoring of regenerative changes. Mitotic figures were counted as the number/10 HPFs and given a score of 1,2 or 3, corresponding to $1-2,3-5$ and $>5$ per $10 \mathrm{HPFs}$. Solid interstitial sheets of cells were given a score of 1,2 or 3, corresponding to $1-2,3-5$ and $>5$ per HPF. Solid tubules were scored as 1,2 or 3 corresponding to $1-2,3-5$ and $>5$ per HPF. Tubules with large vesicular nuclei and tubules lined by cells having hyperchromatic prominent nuclei and little cytoplasm were scored as present or absent.

Scoring of chronic changes. Interstitial fibrosis was scored as 1, 2, 3 or 4 corresponding to a fibrosed interstitium content of $<25,25-50,50-75$ and $>75 \%$, respectively. Tubular atrophy was scored as 1, 2 or 3 corresponding to 1-5, 6-10 and 7-10 per $\mathrm{HPF}$, respectively.

Statistical analysis. Data was analyzed using SPSS software, version 16 (SPSS, Inc., Chicago, IL, USA). Variables were 
Table I. Biochemical values in the three groups at different time points.

\begin{tabular}{|c|c|c|c|c|}
\hline Variable & Sham control $(n=6)$ & Positive control $(n=6)$ & $\operatorname{ADSC}(n=8)$ & P-value \\
\hline \multicolumn{5}{|c|}{ Serum creatinine, $\mathrm{mg} / \mathrm{dl}$} \\
\hline Day 1 & $0.45 \pm 0.24$ & $1.48 \pm 1.30$ & $0.70 \pm 0.12$ & 0.07 \\
\hline Day 3 & $0.40 \pm 0.24$ & $1.54 \pm 1.36^{\mathrm{a}}$ & $0.63 \pm 0.11^{\mathrm{a}, \mathrm{b}}$ & 0.014 \\
\hline Day 7 & $0.42 \pm 0.22$ & $0.68 \pm 0.08^{a}$ & $0.57 \pm 0.09$ & 0.013 \\
\hline Day 14 & & & $0.54 \pm 0.11^{\mathrm{c}}$ & \\
\hline \multicolumn{5}{|c|}{ Creatinine clearance, $\mathrm{ml} / \mathrm{min}$} \\
\hline Day 1 & $2.58 \pm 1.99$ & $0.19 \pm 0.18^{\mathrm{a}}$ & $0.52 \pm 0.33^{\mathrm{a}, \mathrm{b}}$ & $\leq 0.001$ \\
\hline Day 3 & $3.22 \pm 3.18$ & $0.26 \pm 0.07^{\mathrm{a}}$ & $0.52 \pm 0.25^{\mathrm{a}, \mathrm{b}}$ & $\leq 0.001$ \\
\hline Day 7 & $3.78 \pm 2.80$ & $0.57 \pm 0.45^{\mathrm{a}, \mathrm{c}, \mathrm{d}}$ & $0.93 \pm 0.81^{\mathrm{a}}$ & 0.002 \\
\hline Day 14 & & & $1.22 \pm 0.26^{\mathrm{c}, \mathrm{d}}$ & \\
\hline \multicolumn{5}{|c|}{ Serum MDA, nmol/ml } \\
\hline Day 1 & $8.60 \pm 2.90$ & $36.68 \pm 2.70^{\mathrm{a}}$ & $36.93 \pm 5.18^{\mathrm{a}}$ & $\leq 0.001$ \\
\hline Day 3 & $8.90 \pm 1.90$ & $497.60 \pm 70.80^{\mathrm{a}, \mathrm{c}}$ & $41.12 \pm 5.20^{\mathrm{a}, \mathrm{b}}$ & $\leq 0.001$ \\
\hline Day 7 & $10.23 \pm 2.14$ & $40.7 \pm 6.01^{\mathrm{a}}$ & $39.58 \pm 9.09^{\mathrm{a}}$ & $\leq 0.001$ \\
\hline Day 14 & & & $35.60 \pm 6.80$ & \\
\hline \multicolumn{5}{|c|}{ Tissue MDA, nmol/g } \\
\hline Day 1 & $13.10 \pm 5.34$ & $155.90 \pm 22.87^{\mathrm{a}}$ & $91.47 \pm 36.75^{\mathrm{a}, \mathrm{b}}$ & $\leq 0.001$ \\
\hline Day 3 & $13.40 \pm 2.17$ & $199.80 \pm 80.50^{\mathrm{a}}$ & $154.00 \pm 49.30^{\mathrm{a}, \mathrm{c}}$ & $\leq 0.001$ \\
\hline Day 7 & $10.78 \pm 3.50$ & $140.00 \pm 87.90^{\mathrm{a}}$ & $118.45 \pm 29.27^{\mathrm{a}, \mathrm{d}}$ & 0.002 \\
\hline Day 14 & & & $103.20 \pm 30.70^{\mathrm{d}}$ & \\
\hline
\end{tabular}

Data are presented as the mean \pm standard deviation. Two-way analysis of variance tests were used for comparisons among the three groups and within the groups followed by Bonferroni's post-hoc test. ${ }^{\mathrm{a}} \mathrm{P}<0.05 \mathrm{vs}$. the sham group; ${ }^{\mathrm{b}} \mathrm{P}<0.05 \mathrm{vs}$. the positive control group; ${ }^{\mathrm{c}} \mathrm{P}<0.05 \mathrm{vs}$. day 1 within the same group; ${ }^{\mathrm{d}} \mathrm{P}<0.05$ vs. day 3 within the same group. MDA, malondialdehyde; ADSCs, adipose-derived mesenchymal stem cells.

tested for normality distribution using Kolmogrov-Smirnov test. Normally distributed variables were presented as mean \pm standard deviation (SD). Two-way analysis of variance was used for comparisons among the three groups and within the groups followed by Bonferroni's post hoc multiple comparisons. Paired t-test was used for paired comparisons within the same group. $\mathrm{P} \leq 0.05$ was considered statistically significant. Non-parametric variables (pathology scores) were presented as median (minimum-maximum). The Mann-Whitney U test was used for intergroup comparisons and the $\chi^{2}$ test was used for comparisons within the same group.

\section{Results}

Immunophenotypic characterization. Cultures of ADSCs were analyzed for the expression of cell-surface markers. The ADSCs were negative for the hematopoietic lineage marker CD45 (1.63 $\pm 0.18 \%)$, but were positive for CD29 and CD90 (98.7 \pm 2.95 and $92 \pm 1.7 \%$, respectively).

ADSC differentiation capability. ADSCs were observed to differentiate into osteocytes and adipocytes in vitro (Fig. 1) following culture in osteogenic differentiation and adipogenic differentiation media, respectively.

Effect of ADSCs on IRI-induced renal dysfunction as evaluated by serum creatinine levels and creatinine clearance. IRI resulted in a significant increase in serum creatinine levels on days 3 and 7 and a significant reduction in creatinine clearance on days 1, 3 and 7 compared with those in sham-operated rats. These changes were attenuated by the use of ADSCs (Table I).

Effect of ADSCs on IRI-induced oxidative stress as evaluated by MDA levels. IRI resulted in a significant increase in plasma and tissue MDA levels on days 1, 3 and 7 compared with those in sham-operated rats, indicating the occurrence of significant lipid peroxidation secondary to oxidative stress. This was partially ameliorated in the serum by ADSCs at day 3 and in the tissues at days 3 and 7, but remained significantly elevated in the serum and the tissues in comparison with the sham group (Table I).

Effect of ADSCs on IRI-induced renal histopathological changes. The sham group showed an intact brush border with no evidence of necrotic tubules or regenerative changes. The pathology scores were zero for all layers in the sham group.

Histopathological changes occurring following IRI with and without ADSCs treatment are shown in Fig. 2. The histopathological changes in the cortex, ISOM and OSOM generated the highest injury scores, which were significantly evident in the positive control group. The use of ADSCs was associated with significantly lowered injury scores at days 1 and 3, but not on day 7. No significant histopathological differences were observed in the inner medulla between different groups (Tables II and III). 
A

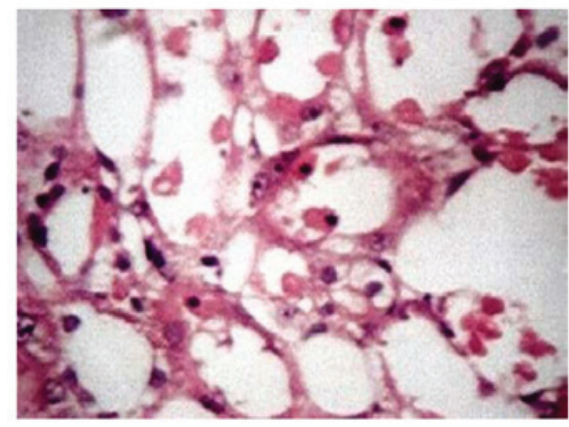

C

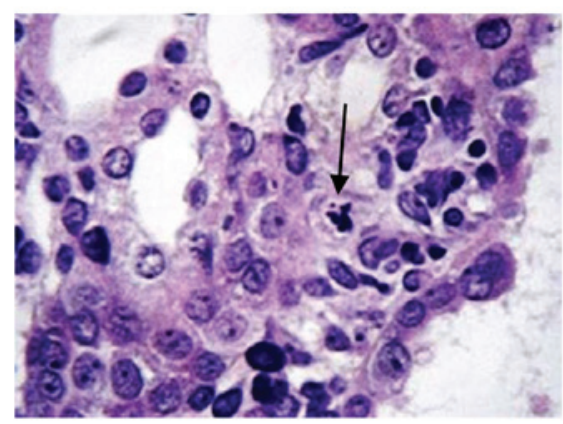

E

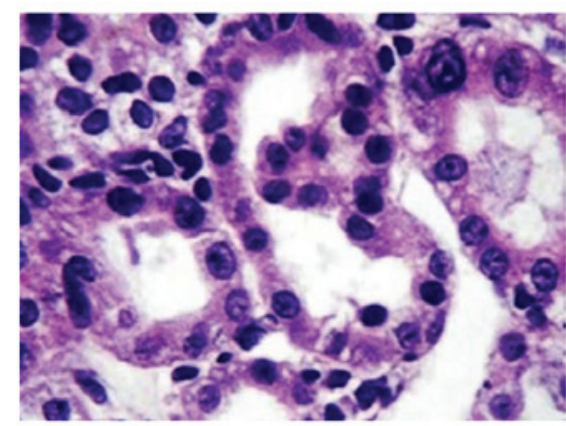

B

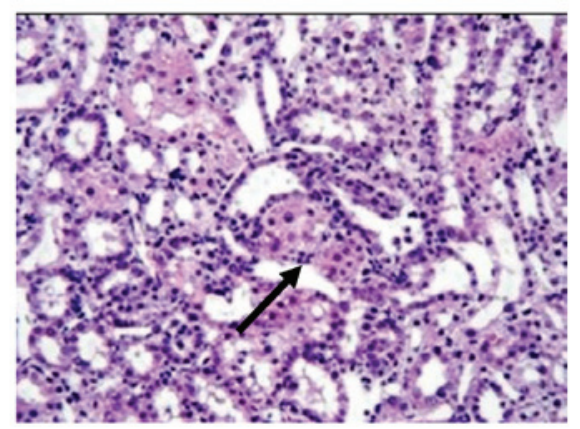

D

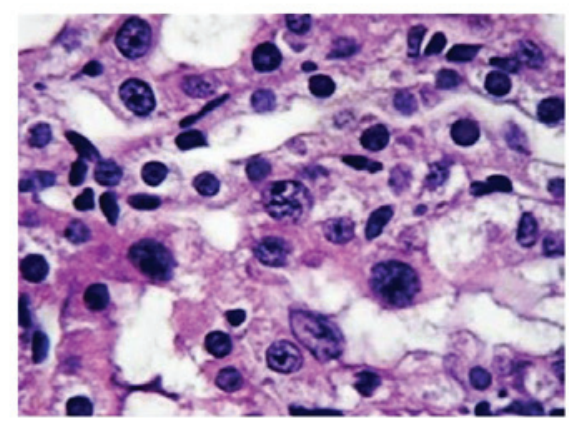

F

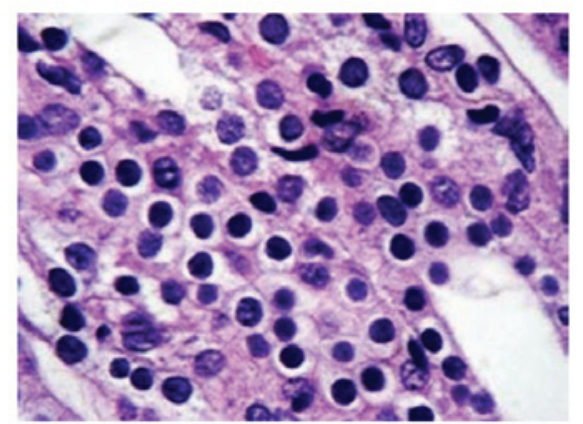

Figure 2. Histopathological changes: Effect of adipose-derived mesenchymal stem cells (ADSCs). (A) The ischemia-reperfusion group shows diffusely necrotic tubules in the outer stripe outer medulla (OSOM) $24 \mathrm{~h}$ after ischemia-reperfusion injury (IRI) (magnification, x100). Histology in the ADSC group shows prominent regenerative changes at 3 days after IRI at the OSOM in the form of (B) solid sheets (magnification, $\mathrm{x} 40$ ), (C) mitotic figures as indicated by the arrow (magnification, $x 400$ ), (D) regenerating cells with large nuclei (magnification, $\mathrm{x} 400$ ) and (E) intraluminal papillary cellular proliferation (magnification, $\mathrm{x} 400$ ), while $(\mathrm{F})$ the inner medulla shows proliferating solid sheets of monotonous cells (magnification, $\mathrm{x} 400$ ).

These data demonstrated that the injury induced by IRI primarily affects the cortex and outer medulla and is potentially reversible and attenuated by the use of ADSCs.

\section{Discussion}

The pathophysiological process of AKI following IRI leads to functional and structural changes that are centered around the proximal tubule cells and endothelium (15). Renal ischemia induces endothelial stress, which leads to swelling of the renal vasculature and consequent narrowing of the lumen with no-reflow phenomenon following the restoration of the renal blood flow (6). Moreover, the constant communication between the tubular epithelium and the vascular endothelium via 'cellular cross-talk' plays a role in the pathogenesis of AKI associated with IRI (6). When exposed to IRI the renal tubular epithelium generates mediators such as tumor necrosis factor (TNF)- $\alpha$, transforming growth factor- $\beta$ and interleukin (IL)-6 that may affect the endothelium directly or by the potentiation of an inflammatory response (6). Although the clinical management of patients with AKI has significantly improved in recent years, specific therapies to enhance kidney repair are lacking. Recovery following acute injury is critical for minimizing patient morbidity and mortality in the hospital setting (16).

The emerging field of regenerative medicine is progressing rapidly and is supported by a large number of studies demonstrating that stem cells have the capacity to substitute for damaged or lost differentiated cells in various organs and tissues (17-20).

Semedo et al (21) demonstrated an anti-inflammatory pattern in MSC-treated animals, indicating the potential of MSCs to modulate IRI, leading to the earlier regeneration of damaged renal tissue.

The aim of the present study was to address the role of ADSCs in AKI secondary to renal IRI. In this study, one million ADSCs were injected into the rats $4 \mathrm{~h}$ following the surgical IRI modeling procedure, and rats were sacrificed on days 1, 3, 7 and 14 after this. The surgery entailed clamping of the renal pedicle for $45 \mathrm{~min}$ in anesthetized rats to cause severe IRI injury in the kidney.

The damaging effects of renal IRI comprise a complex interrelated sequence of events, eventually resulting in both 


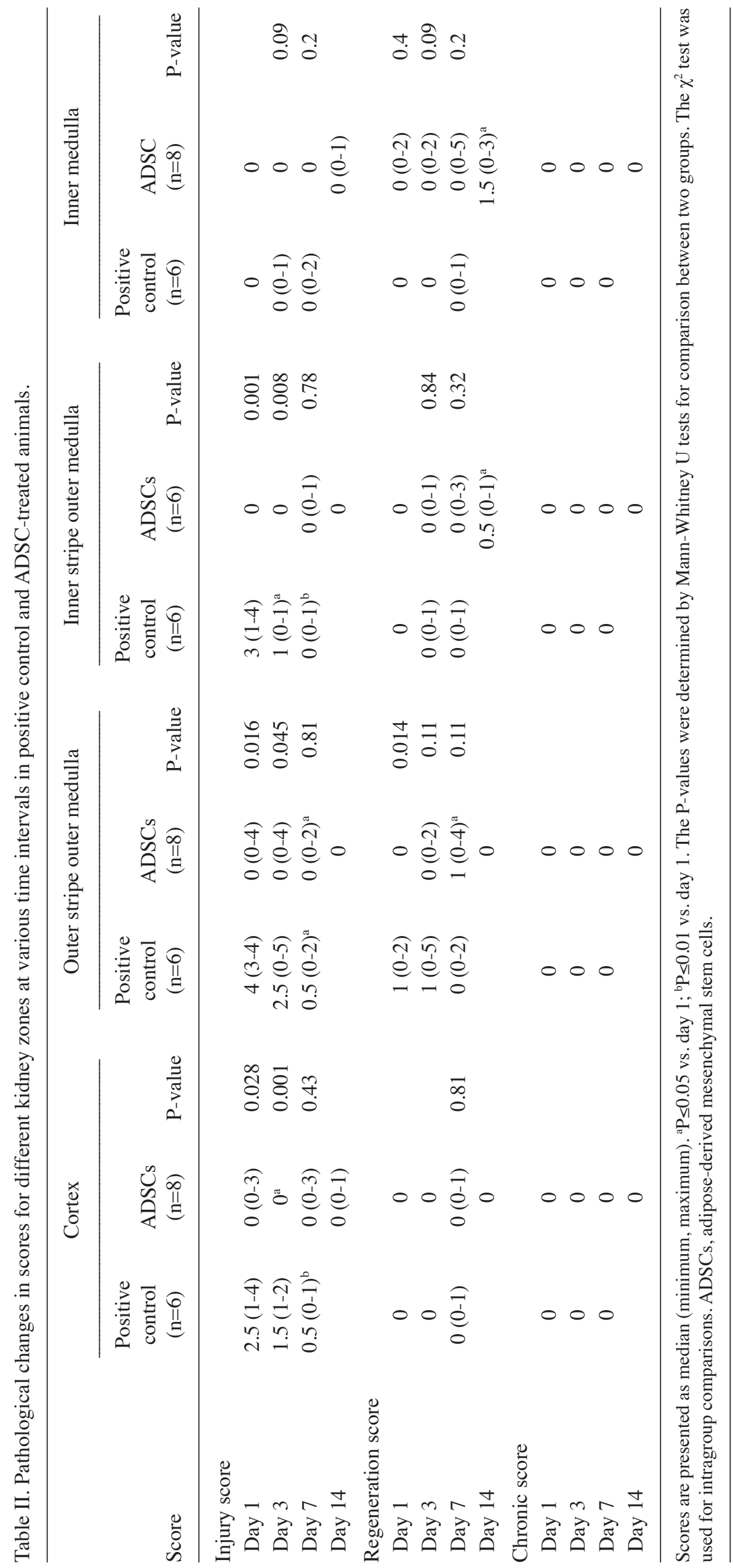


Table III. Total pathological changes in all kidney zones.

\begin{tabular}{|c|c|c|c|}
\hline Score & Positive control $(n=6)$ & $\operatorname{ADSC}(n=8)$ & P-value \\
\hline \multicolumn{4}{|c|}{ Injury score } \\
\hline Day 1 & $9(7-11)$ & $0(0-6)$ & 0.002 \\
\hline Day 3 & $5(1-9)$ & $0(0-4)^{\mathrm{a}}$ & 0.007 \\
\hline Day 7 & $1(0-6)^{b}$ & $0(0-5)$ & 0.7 \\
\hline Day 14 & & $0(0-2)$ & \\
\hline \multicolumn{4}{|c|}{ Regeneration score } \\
\hline Day 1 & $1(0-2)$ & $0(0-2)$ & 0.12 \\
\hline Day 3 & $1.5(0-5)$ & $0(0-5)$ & 0.08 \\
\hline Day 7 & $0(0-5)$ & $2(0-10)^{\mathrm{a}}$ & 0.08 \\
\hline Day 14 & & $2.5(0-3)$ & \\
\hline \multicolumn{4}{|c|}{ Chronic score } \\
\hline Day 1 & 0 & 0 & \\
\hline Day 3 & 0 & 0 & \\
\hline Day 7 & 0 & 0 & \\
\hline Day 14 & & 0 & \\
\hline \multicolumn{4}{|c|}{ Total pathology score } \\
\hline Day 1 & $9.5(8-13)$ & $0(0-6)$ & 0.002 \\
\hline Day 3 & $6.5(1-13)$ & $0(0-9)$ & 0.013 \\
\hline Day 7 & $1(0-11)^{\mathrm{a}}$ & $2(0-11)$ & 0.35 \\
\hline Day 14 & & $2.5(0-5)^{\mathrm{a}}$ & \\
\hline
\end{tabular}

Scores are presented as median (minimum-maximum). ${ }^{\mathrm{a}} \mathrm{P} \leq 0.05$ vs. day $1 ;{ }^{\mathrm{b}} \mathrm{P} \leq 0.01$ vs. day 1 . The $\mathrm{P}$-values were determined by Mann-Whitney $\mathrm{U}$ tests for comparison between groups. The $\chi^{2}$ test was used for intragroup comparisons.

apoptosis and necrosis of the renal cells (5). Thus an ideal modality to manage IRI injury should work by multiple mechanisms.

In the present study, the use of ADSCs was found to be capable of ameliorating renal dysfunction, as demonstrated by improvements of serum creatinine levels and creatinine clearance, and improvement of the histological indices of injury in the renal cortex and outer medulla. Moreover, the use of ADSCs partially ameliorated oxidative stress and lipid peroxidation as reflected by changes in the levels of MDA in the serum and renal tissue. The results are concordant with the results of previous studies. Chen et al (16) demonstrated that ADSC therapy minimized kidney injury following IRI by suppressing oxidative stress and the inflammatory response. Furuichi et al (22) also showed that ADSCs were able to ameliorate AKI induced secondary to IRI in a mouse model via the suppression of cytokines (IL-1 $\beta$ and TNF- $\alpha$ ) and chemokines (microphage inflammatory protein- $1 \alpha$ ), which led to an anti-inflammatory activity and alleviation of tubular necrosis. Based on the ability of cyclosporine to reduce the generation of reactive oxygen species Chen et al (7) administered cyclosporine in addition to ADSCs to mitigate AKI in the setting of IRI in rats, and this combined treatment showed an improved protective effect against acute IRI compared with either treatment alone.

By contrast, in a study conducted in a mouse model by Jiang et al (23), it was concluded that transplantation using hematopoietic stem cells or an MSC cell line did not improve the renal repair process. In addition, the use of stem cells is currently limited by the possible risks associated with the use of stem cell therapy, and controversy exists regarding the exact mechanism underlying the effects of the therapy; thorough scientific exploration is required to assess mechanism, safety profile, reproducibility and methods for monitoring the administered stem cells (8).

Notably, ADSCs exhibit both an early anti-acute insult effect and late regenerative activities, as demonstrated by the results of the present study. Table I indicates a significantly intact renal clearance in the ADSC group at day 1 following renal ischemia-reperfusion, as compared with that of the untreated positive control group. This observation, combined with a notably lower level of MDA in the renal tissue at day 1 is indicative of an early protective mechanism of ADSCs, which may act through antioxidative activity with a consequent anti-inflammatory effect. The histopathological evaluations confirm this finding, as indicated by the significantly lower injury score for the outer stripe of the outer medulla at the day-1 scoring.

The late regenerative stimulant activity of ADSCs is indicated by the markedly significant improvement in the creatinine clearance by the day-14 measurement without a proportional reduction of the tissue MDA level, together with a significant improvement in the regenerative score of the OSOM by day 7 in comparison with the score on day 1 .

In conclusion, the results of the present study demonstrate the ability of ADSCs to ameliorate the renal injury and dysfunction associated with IRI in rats by early protective antioxidative activity and later regenerative stimulant activity. 
However, the major limitations of this study are that molecular studies of the renal tissues were not conducted, and the underlying mechanisms involved in the therapeutic effect of ADSCs against renal IRI remain descriptive. Further investigations, therefore, are warranted to clarify the exact mechanisms underlying the effects of the ADSCs. Since satisfactory treatment modalities for renal IRI are currently lacking, stem cell therapy may be promising provided that gaps in knowledge are filled to assure a safe transition to use in humans.

\section{Acknowledgements}

The present study was supported by the Mansoura University Research and Technology Funding Unit (grant no. 012-09).

\section{References}

1. Palevsky PM: Epidemiology of acute renal failure: The tip of the iceberg. Clin J Am Soc Nephrol 1: 6-7, 2006.

2. Palevsky PM, Molitoris BA, Okusa MD, Levin A, Waikar SS, Wald R, Chertow GM, Murray PT, Parikh CR, Shaw AD, et al: Design of clinical trials in acute kidney injury: Report from an NIDDK workshop on trial methodology. Clin J Am Soc Nephrol 7: 844-850, 2012.

3. Giraud S, Favreau F, Chatauret N, Thuillier R, Maiga S and Hauet T: Contribution of large pig for renal ischemia-reperfusion and transplantation studies: The preclinical model. J Biomed Biotechnol 2011: 532127, 2011.

4. Jang HR, Ko GJ, Wasowska BA and Rabb H: The interaction between ischemia-reperfusion and immune responses in the kidney. J Mol Med (Berl) 87: 859-864, 2009.

5. Sheridan AM and Bonventre JV: Pathophysiology of ischemic acute renal failure. Contrib Nephrol 7-21, 2001.

6. Brodsky SV and Goligorsky MS: Endothelium under stress: Local and systemic messages. Semin Nephrol 32: 192-198, 2012.

7. Chen YT, Yang CC, Zhen YY, Wallace CG, Yang JL, Sun CK Tsai TH, Sheu JJ, Chua S, Chang CL, et al: Cyclosporine-assisted adipose-derived mesenchymal stem cell therapy to mitigate acute kidney ischemia-reperfusion injury. Stem Cell Res Ther 4: 62, 2013

8. Bagul A, Frost JH and Drage M: Stem cells and their role in renal ischaemia reperfusion injury. Am J Nephrol 37: 16-29, 2013.
9. Si YL, Zhao YL, Hao HJ, Fu XB and Han WD: MSCs: Biological characteristics, clinical applications and their outstanding concerns. Ageing Res Rev 10: 93-103, 2011.

10. Bassi G, Pacelli L, Carusone R, Zanoncello J and Krampera M: Adipose-derived stromal cells (ASCs). Transfus Apher Sci 47 193-198, 2012

11. Zuk PA: Stem cell research has only just begun. Science 293: 211-212, 2001.

12. Lotfy A, Salama M, Zahran F, Jones E, Badawy A and Sobh M: Characterization of mesenchymal stem cells derived from rat bone marrow and adipose tissue: A comparative study. Int J Stem Cells 7: 135-142, 2014.

13. Bunnell BA, Flaat M, Gagliardi C, Patel B and Ripoll C: Adipose-derived stem cells: Isolation, expansion and differentiation. Methods 45: 115-120, 2008.

14. Jablonski P, Howden BO, Race DA, Birrel CS, Marshall VC and Tange J: An experimental model for assessment of renal recovery from warm ischemia. Transplantation 35: 198-204, 1983.

15. Semedo P, Palasio CG, Oliveira CD, Feitoza CQ, Gonçalves GM, Cenedeze MA, Wang PM, Teixeira VP, Reis MA, Pacheco-Silva A and Câmara NO: Early modulation of inflammation by mesenchymal stem cell after acute kidney injury. Int Immunopharmacol 9: 677-682, 2009.

16. Chen YT, Sun CK, Lin YC, Chang LT, Chen YL, Tsai TH, Chung SY, Chua S, Kao YH, Yen CH, et al: Adipose-derived mesenchymal stem cell protects kidneys against ischemia-reperfusion injury through suppressing oxidative stress and inflammatory reaction. J Transl Med 9: 51, 2011.

17. Donovan PJ and Gearhart J: The end of the beginning for pluripotent stem cells. Nature 414: 92-97, 2001

18. Goodell MA: Stem-cell 'plasticity': Befuddled by the muddle. Curr Opin Hematol 10: 208-213, 2003.

19. Herzog EL, Chai L and Krause DS: Plasticity of marrow-derived stem cells. Blood 102: 3483-3493, 2003.

20. Weissman IL: Stem cells: Units of development, units of regeneration, and units of evolution. Cell 100: 157-168, 2000.

21. Semedo P, Wang PM, Andreucci TH, Cenedeze MA, Teixeira VP, Reis MA, Pacheco-Silva A and Câmara NO: Mesenchymal stem cells ameliorate tissue damages triggered by renal ischemia and reperfusion injury. Transplant Proc 39: 421-423, 2007.

22. Furuichi K, Shintani H, Sakai Y, Ochiya T, Matsushima K, Kaneko $S$ and Wada T: Effects of adipose-derived mesenchymal cells on ischemia-reperfusion injury in kidney. Clin Exp Nephrol 16: 679-689, 2012.

23. Jiang Y, Jahagirdar BM, Reinhardt RL, Schwartz RE, Keene CD, Ortiz-Gonzalez XR, Reyes M, Lenvik T, Lund T, Blackstad M, et al: Pluripotency of mesenchymal stem cells derived from adult marrow. Nature 418: 41-49, 2002. 